\title{
Publication of a Special Issue 'Glucocorticoids and Melanocortins: Hormones with Important Effects on Immunity'
}

\author{
Claire Redhead \\ TheScientificWorld \\ E-mail: credhead@thescientificworld.com
}

Published September 1, 2007

TheScientificWorldJOURNAL is delighted to have published the special issue 'Glucocorticoids and Melanocortins: Hormones with important effects on immunity', an important collection of peer-reviewed papers covering key topics. The special issue has been organized by Dr Stephen J. Getting (Department of Human and Health Sciences, University of Westminster, London, UK) and investigates the issue explores the role that melanocortins and glucocorticoids play in modulating the host inflammatory response.

Specific topics covered are:

- Antimicrobial Properties of á-MSH and Related Synthetic Melanocortins

- Mode of Glucocorticoid Actions in Airway Disease

- Lipoxins and Annexin-1: Resolution of Inflammation and Regulation of Phagocytosis of Apoptotic Cells

- Annexin 1 and Melanocortin Peptide Therapy for Protection Against Ischaemic-Reperfusion Damage in the Heart

- Dissociated Steroids

- Effects of Glucocorticoids on Apoptosis and Clearance of Apoptotic Cells

The Publisher wishes to express thanks to all of the authors and reviewers, and especially to acknowledge the contribution of Dr. Getting in bringing about the publication of these papers.

\footnotetext{
This article should be cited as follows:

Redhead, C. (2007) Publication of a special issue 'Glucocorticoids and melanocortins: hormones with important effects on immunity’. TheScientificWorldJOURNAL 7, 1465. DOI 10.1100/tsw.2007.235.
} 


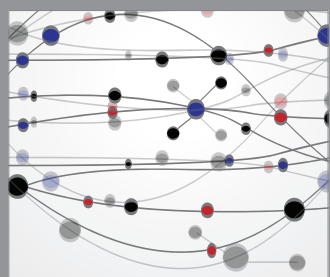

The Scientific World Journal
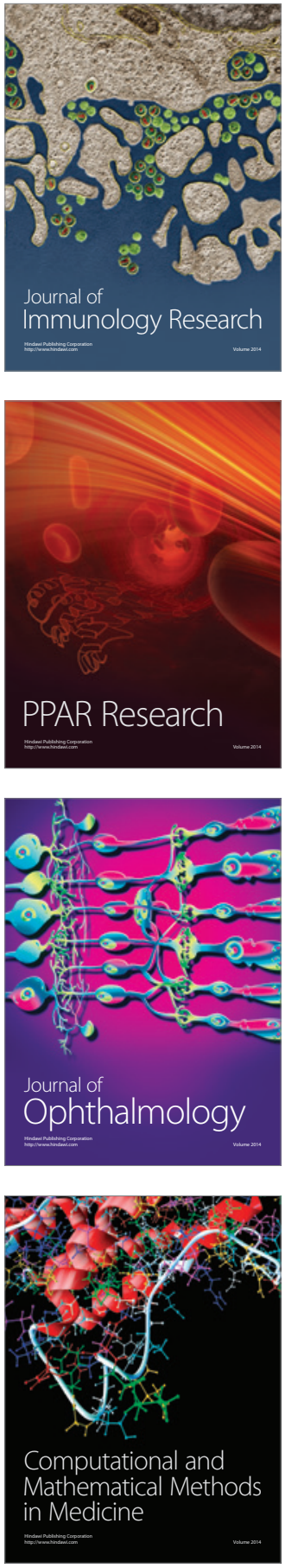

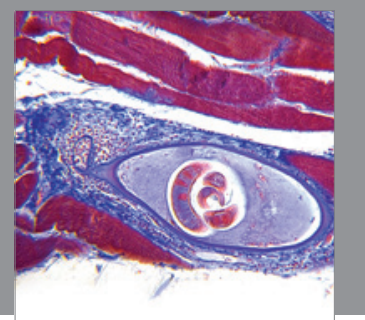

Gastroenterology

Research and Practice
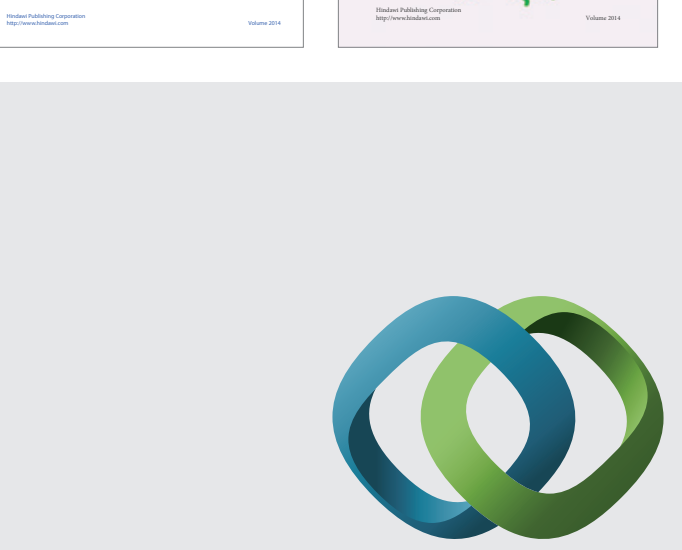

\section{Hindawi}

Submit your manuscripts at

http://www.hindawi.com
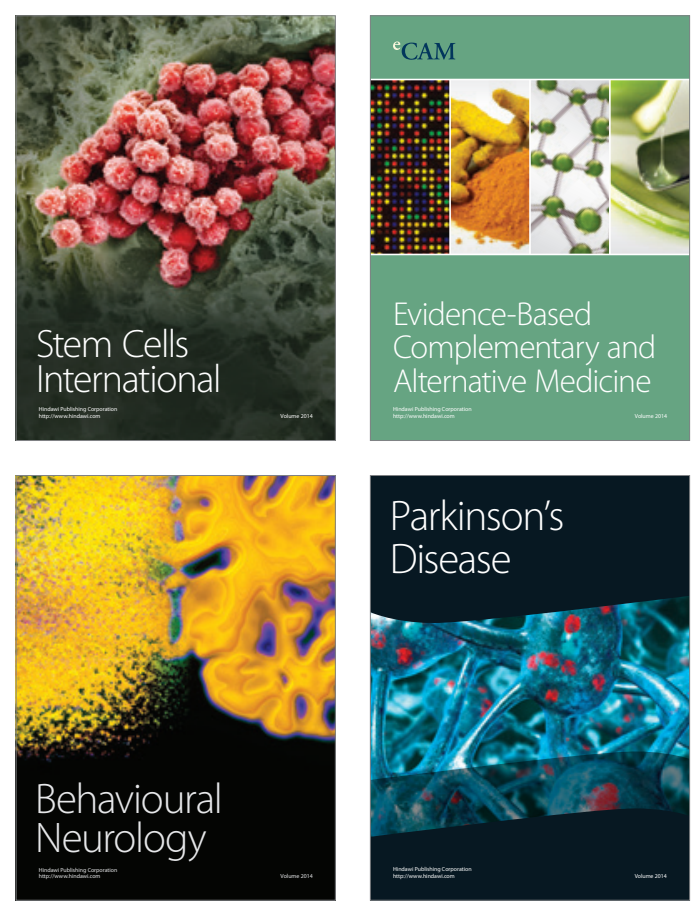

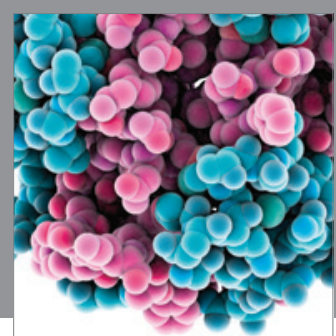

Journal of
Diabetes Research

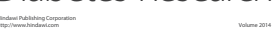

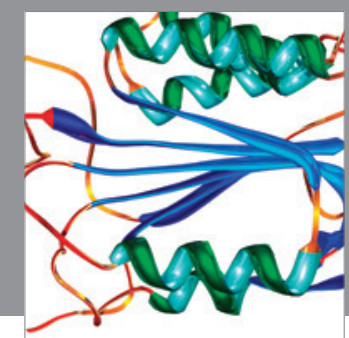

Disease Markers
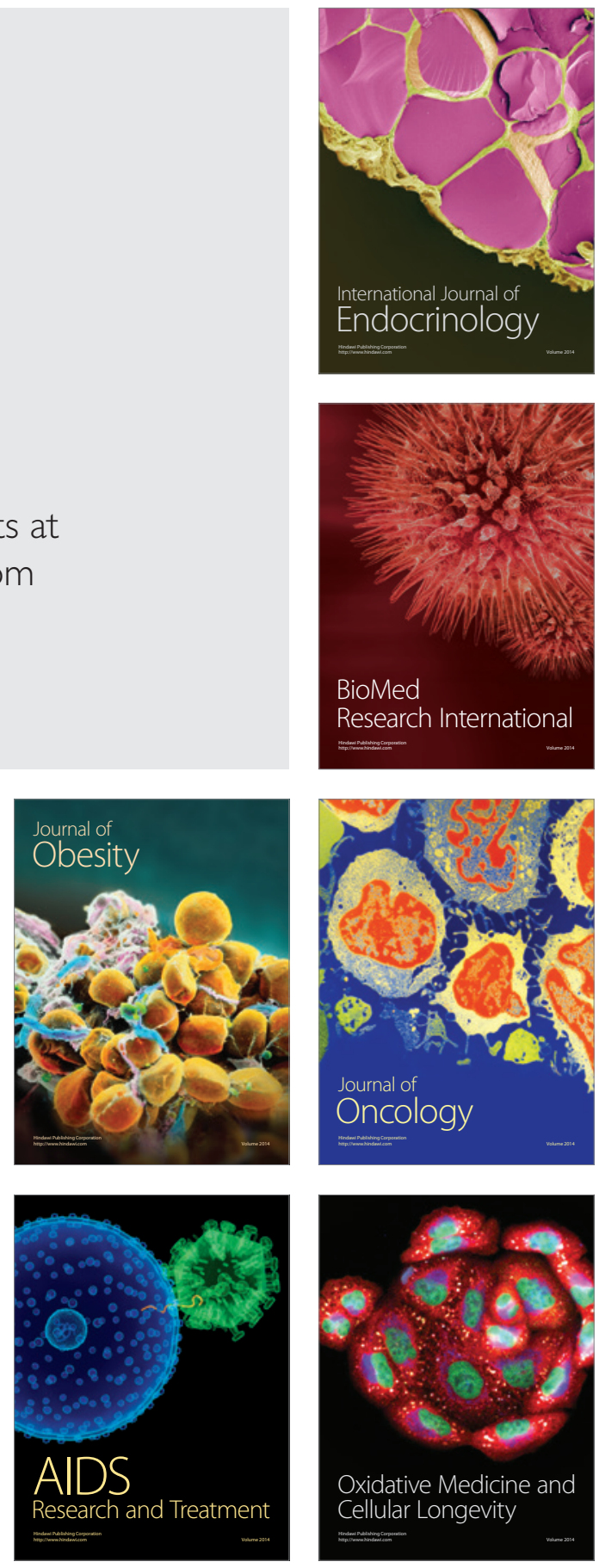